OPEN ACCESS

Edited by:

Giuseppe Reimondo,

University of Turin, Italy

Reviewed by:

Henrik Falhammar,

Karolinska Institutet (KI), Sweden

Miguel Debono,

Royal Hallamshire Hospital, United Kingdom

*Correspondence:

Jung Hee Kim

jhee1@snu.ac.kr:

jhkxingfu@gmail.com

Young Ah Lee

nina337@snu.ac.kr

Specialty section:

This article was submitted to

Adrenal Endocrinology,

a section of the journal

Frontiers in Endocrinology

Received: 19 August 2021 Accepted: 27 September 2021

Published: 12 October 2021

Citation:

Lim SG, Lee YA, Jang HN, Kong SH, Ahn $\mathrm{CH}$, Kim SW, Shin $\mathrm{CH}$ and Kim JH (2021) Long-Term Health Outcomes of Korean Adults With Classic Congenital Adrenal Hyperplasia Due to 21-Hydroxylase Deficiency. Front. Endocrinol. 12:761258. doi: 10.3389/fendo.2021.761258

\section{Long-Term Health Outcomes of Korean Adults With Classic Congenital Adrenal Hyperplasia Due to 21-Hydroxylase Deficiency}

\author{
Seung Gyun Lim 1,2, Young Ah Lee ${ }^{3 *}$, Han Na Jang ${ }^{1,2}$, Sung Hye Kong ${ }^{2,4}$, \\ Chang Ho Ahn ${ }^{2,4}$, Sang Wan Kim ${ }^{2,5}$, Choong Ho Shin ${ }^{3}$ and Jung Hee Kim ${ }^{1,2 *}$ \\ ${ }^{1}$ Department of Internal Medicine, Seoul National University Hospital, Seoul, South Korea, ${ }^{2}$ Department of Internal Medicine, \\ Seoul National University College of Medicine, Seoul, South Korea, ${ }^{3}$ Department of Pediatrics, Seoul National University \\ Children's Hospital, Seoul National University College of Medicine, Seoul, South Korea, ${ }^{4}$ Department of Internal Medicine, \\ Seoul National University Bundang Hospital, Seongnam, South Korea, ${ }^{5}$ Department of Internal Medicine, Seoul Metropolitan \\ Government Seoul National University Boramae Medical Center, Seoul, South Korea
}

There is a lack of studies regarding the long-term outcomes of Asian adults with classic congenital adrenal hyperplasia (CAH) due to 21-hydroxylase deficiency. We hypothesized that adults with $\mathrm{CAH}$ are at higher metabolic risk than their age-, and sex-matched controls. We further investigated the long-term health outcome-related factors in adults with $\mathrm{CAH}$. We compared metabolic risk between adults with $\mathrm{CAH}$ (71 men, 93 women) and age-, and sex-matched controls (190 men, 261 women) from the Korean National Health and Nutrition Examination Survey data. The presence of obesity, testicular adrenal rest tumors (TARTs), and menstrual irregularity was assessed. Hormone status and treatment regimens were compared according to the presence of adverse outcomes. The median age was 27.0 y and 28.0 y for men and women, respectively. Adults with CAH had a higher waist circumference (88.0 vs. $82.3 \mathrm{~cm}$ in men, and $83.5 \mathrm{vs} .72 .3 \mathrm{~cm}$ in women), and blood pressure (125.0 vs. $113.0 \mathrm{mmHg}$ in men, and 120.0 vs. $104.0 \mathrm{mmHg}$ in women) than age- and sex-matched controls ( $P<0.05$ for all). The 2.7-fold increased risk for hypertension (men) and 2.0-fold increased risk for obesity (women) was significant in patients with $\mathrm{CAH}(P<0.05$ for both). Obese adults with $\mathrm{CAH}$ showed significantly higher adrenal limb thicknesses (men) and 17-hydroxyprogesterone and dehydroepiandrosterone sulfate levels (women) $(P<0.05$ for both). TARTs occurred in $58.1 \%$ of men and did not differ by hormone or treatment regimen. Irregular menstruation was observed in $57.1 \%$ of women, with higher dehydroepiandrosterone sulfate levels in 
those with irregular periods. Adults with $\mathrm{CAH}$ had a higher metabolic risk than the general population. Poor disease control may increase their risk of metabolic morbidity and menstrual irregularity.

Keywords: adrenal hyperplasia, congenital, dyslipidemia, hyperglycemia, hypertension, obesity

\section{INTRODUCTION}

Congenital adrenal hyperplasia (CAH) refers to a group of genetic disorders characterized by defective steroidogenesis due to enzyme deficiency. The most common form of CAH, 21-hydroxylase deficiency, affects approximately 1:15,000 live births $(1,2)$. A 21hydroxylase deficiency results in glucocorticoid deficiency and an increase in pituitary adrenocorticotropin (ACTH) secretion, leading to adrenal androgen excess and adrenal hyperplasia. Depending on disease severity, CAH due to 21-hydroxylase deficiency is classified into classic (salt-wasting and simple virilizing) and non-classic forms (1). The early diagnosis of 21hydroxylase deficiency through newborn screening test using 17 hydroxyprogesterone (17-OHP) has decreased mortality and morbidity rates, leading to increased interest in improving longterm health outcomes in adulthood $(1,2)$.

Several studies have reported adverse outcomes in adults with $\mathrm{CAH}$. In the United Kingdom Congenital Adrenal Hyperplasia Adult Study Executive (CaHASE), 203 adults with CAH were significantly shorter and had a higher body mass index (BMI) compared to the health survey data (3). In a Swedish study, based on disease codes, 360 adults with CAH had an approximately four-fold higher risk of having any cardiovascular and metabolic disorders than matched controls (4). In a cross-sectional study of the National Institutes of Health (NIH) and French cohort, the prevalence of obesity was common, ranging from $35 \%$ to $44 \%$ (5, 6), although the latter two studies did not compare the patients' metabolic risk with that of healthy controls. In a European multicenter study, 226 adults with CAH were a higher risk for hypertension, dyslipidemia, and cardiovascular disease but not type 2 diabetes (7). A recent meta-analysis including children and adults with $\mathrm{CAH}$ demonstrated that these patients had a high prevalence of cardiovascular and metabolic risk factors (8).

The two main goals for $\mathrm{CAH}$ management are to replace the deficient hormones for adrenal insufficiency and control androgen excess. However, it is challenging to balance glucocorticoid doses because supraphysiologic doses of glucocorticoids are usually required to suppress androgen excess. It remains controversial whether over- or undertreatment is more harmful to the metabolic and cardiovascular health of patients with CAH $(3,5,6,9-11)$. Moreover, the relationship between testicular adrenal rest tumors (TARTs) and disease control remains unclear $(5,6,12)$.

Most related studies have not performed a sex-stratified analysis and rarely evaluated adrenal morphology such as hyperplasia or thinning $(6,13)$. In Asia, few studies have examined the determining factors for adverse outcomes in adults with $\mathrm{CAH}$. In this context, we hypothesized that adults with $\mathrm{CAH}$ are at a higher risk of metabolic morbidity than their age- and sex-matched controls in the Asian general population.
Furthermore, we aimed to investigate sex-specific indicators related to adverse health outcomes by focusing on metabolic morbidity, TARTs, and menstrual irregularity in adults with CAH.

\section{MATERIALS AND METHODS}

\section{Study Subjects}

Among the 233 adults with $\mathrm{CAH}$ aged over 20 years at the last follow-up visit between 2000 and 2020 at Seoul National University Hospital, those with non-classic CAH $(n=19)$ or for whom laboratory findings or an appropriate medical history was lacking $(n=50)$ were excluded. Finally, we included 164 adults with classic 21 -hydroxylase deficiency. Of the 71 men and 93 women included in this study 42 (59.2\%) men and 34 (36.6\%) women had salt-wasting form. We diagnosed patients with CAH based on clinical and biochemical data since the genetic testing for CYP21A2 mutation was only done in 34 of 164 patients. All patients were diagnosed clinically since neonatal screening was first introduced in 2006 in Korea. For comparison, age- and sexmatched controls (190 men, 261 women) were included in this study, with a 1:3 case to control ratio from the nationwide representative survey database (Korean National Health and Nutrition Examination Survey [KNHANES] 2015) (14).

\section{Clinical, Imaging, and Biochemical Data}

We retrospectively reviewed the patients' electronic medical records and retrieved the data from the last follow-up visit. BMI was calculated as body weight divided by height squared $\left(\mathrm{kg} / \mathrm{m}^{2}\right)$. Waist circumference was measured at the level of the umbilicus with the subject standing and breathing normally while wearing light clothing. Blood pressure was measured twice on different days using an automated technique while the subjects were in a seated position after a 20-min rest. Body composition data, such as lean mass and fat mass, were obtained from a bioimpedance analyzer (Inbody $720^{\circledR}$; Inbody Co. Korea).

Obesity was defined as a BMI $>25 \mathrm{~kg} / \mathrm{m}^{2}(15)$. Dyslipidemia was defined as the use of lipid-lowering agents or having an abnormal lipid panel (total cholesterol $\geq 240 \mathrm{mg} / \mathrm{dL}$, LDL cholesterol $\geq 160 \mathrm{mg} / \mathrm{dL}$, triglycerides $\geq 200 \mathrm{mg} / \mathrm{dL}$, or HDL cholesterol $<40 \mathrm{mg} / \mathrm{dL}$ ). The presence of hyperglycemia included diabetes mellitus and prediabetes. Diabetes mellitus was defined as an HbAlc $\geq 6.5 \%$ or the use of any oral antidiabetic drugs or insulin therapy. Prediabetes was determined as an $\mathrm{HbAlc}$ value between $5.7 \%$ and $6.4 \%$ or a fasting plasma glucose $\geq 100 \mathrm{mg} / \mathrm{dL}$. Subjects taking any antihypertensive medications or systolic blood pressure $\geq 130 \mathrm{mmHg}$ and/or diastolic blood pressure $\geq 85 \mathrm{mmHg}$ in repeated measurements 
were considered to have hypertension (16). In men, TARTs were identified using testicular sonography. In women, the regularity of menstruation was classified into two categories: regular (21-35 days) or irregular (oligomenorrhea/amenorrhea).

Computed tomography was performed to evaluate the morphology of the adrenal glands. The examiner was blinded to the patients' history. The widths of the medial and lateral adrenal limbs were measured as the maximum width of the limbs perpendicular to the long axis (17). The thickness of the adrenal limb was defined as the mean medial and lateral limb widths. The current glucocorticoid and mineralocorticoid (fludrocortisone) regimen was identified for each patient. The daily glucocorticoid dose was calculated based on glucocorticoid type and daily dose. Glucocorticoid doses were calculated based on the antiinflammatory equivalent dose compared to hydrocortisone (30 $\mathrm{mg}$ hydrocortisone $=7.5 \mathrm{mg}$ prednisolone) .

Morning fasting blood samples were taken before steroid medications were administered. Laboratory tests included hemoglobin A1c (HbA1c), plasma glucose, total cholesterol, triglycerides, high-density lipoprotein (HDL) cholesterol, lowdensity lipoprotein (LDL) cholesterol, 17-hydroxyprogesterone (17-OHP), total testosterone, dehydroepiandrosterone sulfate (DHEAS), plasma renin activity, and adrenocorticotropin (ACTH).

\section{Biochemical assays}

Serum 17-OHP and DHEAS levels were measured using a radioimmunoassay (RIA) CT kit (Asbach Medical Products $\mathrm{GmbH}$, Germany), with intra- and inter-assay CVs of $4.6-6.8 \%$ and $7.7-8.8 \%$ for $17-\mathrm{OHP}$ (reference range, $0.11-5.00 \mathrm{ng} / \mathrm{mL}$ ) and $3.6-5.9 \%$ and $6.5 \%$ for DHEAS (reference range, 1187-4289 ng/ $\mathrm{mL}$ ), respectively. Serum total testosterone was measured using a TESTO-CT2 kit (Cisbio Bioassays, Saclay, France) with intra- and inter-assay CVs of $3.1-8.9 \%$ and $5.2-11.6 \%$, respectively (reference range, $2.7-10.7 \mathrm{ng} / \mathrm{mL}$ in men, and $0-1.0 \mathrm{ng} / \mathrm{mL}$ in women). Plasma renin activity was measured using a PRA RIA kit (TFB, Inc.), with intra- and inter-assay CVs of $3.8 \%$ and $6.7 \%$, respectively (reference range, $0.32-1.84 \mathrm{ng} / \mathrm{mL} / \mathrm{hr}$ ). Plasma ACTH was measured using an immunoradiometric assay (Cisbio Bioassays) with a reference range of 10.0-60.0 pg/mL. The intra- and inter-assay CVs of the ACTH used were $3.7 \%$ and $3.8 \%$, respectively.

\section{Statistical Analysis}

Data are shown as number (percentage) for categorical variables and mean \pm standard deviation or median (interquartile range) for continuous variables based on the results of the normality test. The normality test was performed using the Shapiro-Wilk test. Categorical variables were analyzed using the chi-squared test. Continuous variables were compared using Student's t-test or the Mann-Whitney $U$ test according to the distribution of normality. Logistic regression models were constructed to assess the metabolic risk of patients with CAH by sex. To adjust for the effect of age and BMI, we performed a multivariate logistic regression analysis, and age and $\mathrm{BMI}$-adjusted odds ratio (OR) and $95 \%$ confidence interval $(95 \% \mathrm{CI})$ are presented. Statistical significance was set at $\mathrm{P}<0.05$. All statistical analyses were performed using R Statistical Software (version 4.0.3).

\section{RESULTS}

\section{Comparison of Metabolic Risk Between Patients with $\mathrm{CAH}$ and Healthy Controls}

Table 1 compares the clinical and biochemical characteristics of patients with $\mathrm{CAH}$ and age- and sex-matched controls by sex. The median age for men and women was 27.0 and 28.0 years, respectively. The men with $\mathrm{CAH}(\mathrm{n}=71)$ exhibited a shorter stature $(\mathrm{P}<0.001)$, higher weight, and greater waist circumference ( $\mathrm{P}=0.005$ for both) than the control men ( $\mathrm{n}=$ 190) without a BMI difference. Fasting plasma glucose and blood pressure were higher in the men with $\mathrm{CAH}(\mathrm{P}<0.05)$, but HbAlc was similar between the two groups. Although total cholesterol, triglyceride, and LDL cholesterol levels were similar between the two groups, HDL cholesterol was higher in the men with $\mathrm{CAH}$ than in the control men $(\mathrm{P}<0.001)$.

The women with $\mathrm{CAH}(\mathrm{n}=93)$ showed a shorter stature, higher BMI, and higher waist circumference $(\mathrm{P}<0.05)$ than the

TABLE 1 | Comparison of clinical characteristics between CAH patients and age- and sex-matched control.

\begin{tabular}{|c|c|c|c|c|c|c|}
\hline Variables & $\begin{array}{c}\text { CAH men } \\
(\mathrm{N}=71)\end{array}$ & $\begin{array}{l}\text { Control men } \\
(N=190)\end{array}$ & $\boldsymbol{P}$ & $\begin{array}{l}\text { CAH women } \\
\quad(N=93)\end{array}$ & $\begin{array}{l}\text { Control women } \\
\qquad(N=261)\end{array}$ & $\mathbf{P}$ \\
\hline Age, years & $27.0[23.0 ; 33.0]$ & $27.0[23.0 ; 33.0]$ & 0.918 & $28.0[23.0 ; 36.0]$ & $28.0[23.0 ; 36.0]$ & 0.937 \\
\hline Height, cm & $163.8[157.6 ; 167.9]$ & $174.7[170.5 ; 177.8]$ & $<0.001$ & $152.8[147.6 ; 157.6]$ & $160.3[157.0 ; 164.6]$ & $<0.001$ \\
\hline Weight, kg & $66.3[57.0 ; 76.9]$ & $71.5[65.0 ; 79.7]$ & 0.005 & $54.0[46.2 ; 59.3]$ & $55.7[50.6 ; 62.8]$ & 0.020 \\
\hline Body mass index, kg/m ${ }^{2 \star}$ & $23.8[21.2 ; 30.0]$ & $23.3[21.6 ; 26.0]$ & 0.111 & $23.2[20.2 ; 25.7]$ & $21.4[19.7 ; 23.6]$ & 0.006 \\
\hline Waist circumference, $\mathrm{cm}^{\star}$ & $88.0[78.0 ; 97.5]$ & $82.3[77.2 ; 89.4]$ & 0.005 & $83.5[77.0 ; 92.0]$ & $72.3[67.4 ; 79.3]$ & $<0.001$ \\
\hline Systolic blood pressure, $\mathrm{mmHg}$ & $125.0[120.5 ; 135.0]$ & $113.0[106.0 ; 122.0]$ & $<0.001$ & $120.0[112.0 ; 130.0]$ & $104.0[99.0 ; 110.0]$ & $<0.001$ \\
\hline Diastolic blood pressure, $\mathrm{mmHg}$ & $77.0[73.0 ; 85.0]$ & $73.0[68.0 ; 81.0]$ & 0.007 & $75.0[67.0 ; 82.0]$ & $70.0[64.0 ; 75.0]$ & $<0.001$ \\
\hline Fasting plasma glucose, mg/dL & $94.0[89.0 ; 99.0]$ & $91.0[87.0 ; 96.0]$ & 0.030 & $89.0[86.0 ; 96.0]$ & $88.0[84.0 ; 93.0]$ & 0.234 \\
\hline $\mathrm{HbA1c}, \%$ & $5.2[5.1 ; 5.4]$ & $5.3[5.1 ; 5.5]$ & 0.067 & $5.2[5.0 ; 5.4]$ & $5.3[5.1 ; 5.5]$ & 0.013 \\
\hline Total cholesterol, mg/dL & $188.9 \pm 34.2$ & $180.7 \pm 31.2$ & 0.070 & $190.0[167.0 ; 217.0]$ & $180.0[158.0 ; 202.0]$ & 0.007 \\
\hline Triglyceride, mg/dL & $114.0[85.0 ; 151.0]$ & $104.0[74.5 ; 175.0]$ & 0.503 & 108.0 [83.0;139.0] & 71.0 [55.0;100.0] & $<0.001$ \\
\hline HDL cholesterol, mg/dL & $55.0[49.0 ; 69.0]$ & $47.3[40.8 ; 55.4]$ & $<0.001$ & $65.1 \pm 16.1$ & $58.7 \pm 12.6$ & 0.001 \\
\hline LDL cholesterol, mg/dL & $109.0[93.0 ; 128.5]$ & $109.0[91.0 ; 126.5]$ & 0.832 & $113.0[95.5 ; 134.0]$ & $103.0[84.0 ; 124.0]$ & 0.058 \\
\hline
\end{tabular}

Data are shown as mean \pm standard deviation, median (interquartile range), or numbers (percentages). CAH, congenital adrenal hyperplasia; HDL, high-density lipoprotein; LDL, lowdensity lipoprotein; *Body mass index and waist circumference were not available in 12 and 54 patients with CAH. 
TABLE 2 | Metabolic risks in CAH adults compared with age- and sex-matched controls.

\begin{tabular}{|c|c|c|}
\hline & Men & Women \\
\hline Obesity & $1.58(0.89-2.80)$ & $2.04(1.18-3.50)$ \\
\hline Dyslipidemia & $0.81(0.44-1.44)$ & $1.17(0.61-2.14)$ \\
\hline Hyperglycemia & $0.81(0.42-1.51)$ & $1.25(0.70-2.17)$ \\
\hline Hypertension & $2.67(1.22-5.82)$ & $1.84(0.78-4.17)$ \\
\hline
\end{tabular}

Data are shown as odds ratios (95\% confidence interval). CAH, congenital adrenal hyperplasia; OR, odds ratio. *BMI was not available in 12 patients.

control women $(n=261)$. Blood pressure was also higher in the women with $\mathrm{CAH}$ than in the control women $(\mathrm{P}<0.001)$. Fasting plasma glucose levels were similar between the two groups, but $\mathrm{HbAlc}$ was lower in women with $\mathrm{CAH}(\mathrm{P}<$ 0.013). Total cholesterol, triglyceride, and HDL cholesterol levels were higher in the women with $\mathrm{CAH}$ than in the control women $(\mathrm{P}<0.05)$.

We analyzed the metabolic outcomes of the $\mathrm{CAH}$ group versus the control group (Table 2). The CAH group had a two-fold higher risk of obesity than the control group among the women (OR [95\% CI], 2.04 [1.18-3.50]), but the difference was not significant in the men. The increased risk of hypertension was found in $\mathrm{CAH}$ men (OR [95\% CI], 2.67 [1.22-5.82]) but not in women. The risk of dyslipidemia and hyperglycemia did not differ between the two groups in either sex.

\section{Comparison According to Whether CAH Patients Have Metabolic Comorbidities}

Figure 1 shows the prevalence of comorbidities in adults with $\mathrm{CAH}$. The prevalence of any metabolic comorbidity was significantly higher in men than in women $(70.4 \%$ vs. $52.7 \%$, $\mathrm{P}=0.032$ ) without sex differences for each component. The prevalence of obesity, dyslipidemia, hyperglycemia, and hypertension was $43.9 \%, 29.6 \%, 23.9 \%, 19.7 \%$ in men and $33.7 \%, 18.3 \%, 23.7 \%, 10.8 \%$ in women, respectively. The number of patients with diabetes was only 6 in women and 2

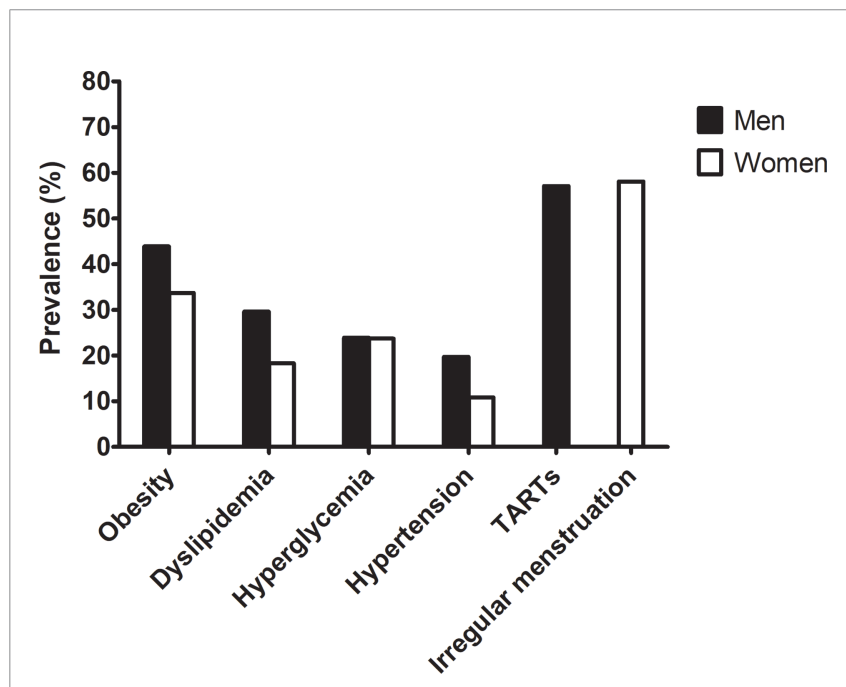

FIGURE 1 | Prevalence of metabolic risk and gonadal dysfunction in the adult $\mathrm{CAH}$ patients according to sex. in men with CAH. There was no history of gestational diabetes, cardiovascular or cerebrovascular disease.

We further analyzed the differences in hormone status and treatment regimen according to whether $\mathrm{CAH}$ patients were obese (Table 3). Neither age at diagnosis nor proportion of subtypes differed between obese and non-obese patients. Obese adults with $\mathrm{CAH}$ had a higher waist circumference and percentage of fat mass in both sexes but a lower percentage of lean mass than those without ( $\mathrm{P}<0.05$ for all for both sexes). Adrenal limb thickness was significantly higher in obese men compared to non-obese men $(\mathrm{P}<0.001)$. Although the difference of adrenal limb thickness was marginally significant between obese and non-obese women, adrenal tumors was more frequently found in obese women compared to non-obese women $(\mathrm{P}=0.019)$. Among the hormones, 17-OHP and DHEAS levels were significantly higher in obese women than in non-obese ones $(\mathrm{P}<0.001$, and $\mathrm{P}=0.009$, respectively). All obese women had a $17-\mathrm{OHP}$ level $\geq$ of $10 \mathrm{ng} / \mathrm{mL}$. However, the glucocorticoid regimen and dose were not related to obesity in either sex. The number of patients with 0,1 , and $\geq 2$ metabolic comorbidities was $29.6 \%(n=21), 35.2 \%(n=25)$, and $35.2 \%$ $(\mathrm{n}=25)$ in men with CAH, and $47.3 \%(\mathrm{n}=44), 26.8 \%(\mathrm{n}=25)$, and $25.8 \%(n=24)$ in women with $\mathrm{CAH}$, respectively. No significant relationships of age at diagnosis, proportion of subtypes, and glucocorticoid doses with number of metabolic comorbidities were found in both sex (data not shown).

\section{Comparison of Whether CAH Patients Had TARTs or Menstrual Irregularities}

The prevalence of TARTs in men was 58.1\% (Figure $\mathbf{1}$ and Table 4). The presence of TARTs was not related to disease control, hormone status, glucocorticoid regimen, or adrenal limb thickness in men. Among the women, 57.1\% exhibited menstrual irregularities (Figure 1 and Table 4). Women with irregular periods showed a shorter stature and a higher DHEAS level than those with regular periods ( $\mathrm{P}<0.05$ for both). Other hormones, steroid regimens, and adrenal limb thickness did not differ according to menstrual regularity.

\section{DISCUSSION}

The present study suggested that waist circumference and blood pressure were higher in adults with $\mathrm{CAH}$ compared with ageand BMI-matched controls from the KNHANES database. Moreover, there was an increased risk of hypertension in men and obesity in women with $\mathrm{CAH}$ than controls. Obese men with 
TABLE 3 | Hormone status and treatment regimens in CAH men and women according to the presence of obesity.

\begin{tabular}{|c|c|c|c|c|c|c|}
\hline \multirow[t]{2}{*}{ Variables } & \multicolumn{3}{|c|}{ Men } & \multicolumn{3}{|c|}{ Women } \\
\hline & $\begin{array}{c}\text { Obesity (-) } \\
(\mathbf{N}=37)\end{array}$ & $\begin{array}{c}\text { Obesity (+) } \\
(\mathrm{N}=29)\end{array}$ & $P$ & $\begin{array}{c}\text { Obesity (-) } \\
(N=57)\end{array}$ & $\begin{array}{l}\text { Obesity (+) } \\
(\mathrm{N}=29)\end{array}$ & $P$ \\
\hline Age at evaluation, years & $26.0[23.0 ; 31.0]$ & $28.0[24.0 ; 37.0]$ & 0.164 & $28.0[22.0 ; 35.0]$ & 32.0 [24.0;41.0] & 0.177 \\
\hline Age at diagnosis, years & $1.0[0.0 ; 7.0]$ & $1.0[0.0 ; 8.0]$ & 0.520 & $2.0[0.0 ; 10.0]$ & 5.0 [1.0; 17.0] & 0.149 \\
\hline Salt-wasting form, n (\%) & $21(56.8 \%)$ & $18(62.1 \%)$ & 0.854 & $23(40.4 \%)$ & $10(34.5 \%)$ & 0.768 \\
\hline Height, cm & 163.9 [157.6;168.3] & $163.2[158.9 ; 167.8]$ & 0.846 & $152.5[147.2 ; 157.0]$ & $155.0[148.8 ; 158.6]$ & 0.419 \\
\hline Weight, kg & $57.4[53.2 ; 61.0]$ & $79.8[73.5 ; 87.1]$ & $<0.001$ & $50.2[43.1 ; 54.6]$ & $63.9[58.4 ; 70.6]$ & $<0.001$ \\
\hline Body mass index, $\mathrm{kg} / \mathrm{m}^{2}$ & $21.7[20.6 ; 23.4]$ & $30.4[28.1 ; 31.5]$ & $<0.001$ & $21.0 \pm 2.6$ & $28.5 \pm 3.5$ & $<0.001$ \\
\hline Waist circumference (cm) & $80.0 \pm 5.6$ & $98.8 \pm 6.6$ & $<0.001$ & 79.0 [75.0;87.0] & 90.0 [84.0;105.0] & $<0.001$ \\
\hline Lean mass $(\mathrm{kg})$ & $24.7[23.6 ; 26.5]$ & $28.7[26.7 ; 31.3]$ & 0.001 & $18.4[16.7 ; 21.0]$ & $23.3[20.8 ; 29.4]$ & $<0.001$ \\
\hline Percentage lean mass (\%) & $42.6[40.3 ; 46.4]$ & $36.4[34.3 ; 38.4]$ & $<0.001$ & $36.9[34.2 ; 39.9]$ & $33.0[29.8 ; 57.3]$ & 0.054 \\
\hline Fat mass $(\mathrm{kg})$ & $15.4 \pm 4.6$ & $29.1 \pm 6.5$ & $<0.001$ & $19.5[16.2 ; 22.2]$ & $25.0[22.5 ; 35.5]$ & $<0.001$ \\
\hline Percentage fat mass (\%) & $25.0 \pm 6.1$ & $36.5 \pm 5.8$ & $<0.001$ & $36.0 \pm 6.2$ & $41.1 \pm 6.9$ & 0.006 \\
\hline 17-OHP, ng/mL & $60.0[31.1 ; 83.9]$ & $81.6[56.2 ; 105.3]$ & 0.055 & $38.3[20.3 ; 60.7]$ & $71.8[44.3 ; 109.0]$ & $<0.001$ \\
\hline 17-OHP <10 ng/mL (\%) & $2(5.4 \%)$ & $1(3.5 \%)$ & 1.000 & $9(15.8 \%)$ & $0(0.0 \%)$ & 0.026 \\
\hline Total testosterone, ng/mL & $4.3[3.5 ; 6.5]$ & $4.7[3.7 ; 5.4]$ & 0.838 & $0.5[0.1 ; 0.9]$ & $0.7[0.5 ; 1.8]$ & 0.138 \\
\hline DHEAS, ng/mL & 736.0 [277.0;1351.0] & $686.5[295.5 ; 1435.0]$ & 0.639 & $292.0[105.5 ; 743.5]$ & 632.0 [306.0;1690.0] & 0.009 \\
\hline Plasma renin activity, $\mathrm{ng} / \mathrm{mL} / \mathrm{hr}$ & $7.4[3.4 ; 10.4]$ & $10.7[5.4 ; 21.4]$ & 0.077 & $8.4[4.2 ; 11.9]$ & $8.2[4.8 ; 15.4]$ & 0.428 \\
\hline Plasma renin activity $<3 \mathrm{ng} / \mathrm{mL} / \mathrm{hr}$ & 7 (20.0\%) & $7(7.1 \%)$ & 0.277 & $8(14.3 \%)$ & $2(8.3 \%)$ & 0.715 \\
\hline $\mathrm{ACTH}, \mathrm{pg} / \mathrm{mL}$ & $117.2[40.5 ; 281.3]$ & $232.6[81.9 ; 681.0]$ & 0.164 & $33.1[14.9 ; 232.7]$ & $70.2[37.4 ; 188.0]$ & 0.228 \\
\hline Adrenal thickness on CT, mm & $5.5[4.1 ; 6.3]$ & $7.4[6.1 ; 8.9]$ & $<0.001$ & $5.8[4.5 ; 7.3]$ & $6.7[5.3 ; 9.2]$ & 0.064 \\
\hline Adrenal tumors, n (\%) & $3(12.0 \%)$ & $5(26.3 \%)$ & 0.262 & $1(2.9 \%)$ & $4(28.6 \%)$ & 0.019 \\
\hline Glucocorticoid regimen, n (\%) & & & 1.000 & & & 1.000 \\
\hline Hydrocortisone & $1(2.7 \%)$ & 0 ( $0.0 \%)$ & & $5(8.8 \%)$ & $3(10.3 \%)$ & \\
\hline Prednisolone & $36(97.3 \%)$ & 29 (100.0\%) & 0.850 & $52(91.2 \%)$ & $26(89.7 \%)$ & 0.400 \\
\hline Glucocorticoid dose, mg/day & $30.0[20.0 ; 30.0]$ & $30.0[20.0 ; 30.0]$ & 0.850 & $30.0[20.0 ; 30.0]$ & $25.0[20.0 ; 30.0]$ & 0.400 \\
\hline Fludrocortisone use, n (\%) & $31(83.8 \%)$ & $22(75.9 \%)$ & 0.623 & $43(75.4 \%)$ & $14(48.3 \%)$ & 0.023 \\
\hline
\end{tabular}

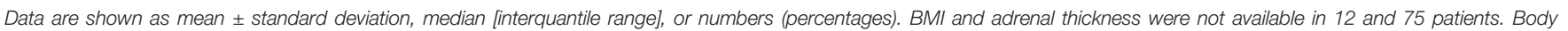
composition data were not available in 20 men and 38 women. 17-OHP, 17-hydroxyprogesterone; DHEAS, dehydroepiandrosterone sulfate.

CAH showed higher adrenal limb thicknesses than non-obese ones, while obese women had higher 17-OHP and DHEAS levels than non-obese ones. In addition, more than half of the adults with CAH exhibited TARTs or menstrual irregularities. The presence of TARTs in men with $\mathrm{CAH}$ was not related to disease control, while women with $\mathrm{CAH}$ who had irregular periods were shorter and had higher DHEAS levels than those with regular periods.

The prevalence of obesity or central obesity in adults with classic CAH is reportedly $20-50 \%$, higher than that in healthy controls (3-6). In the present study, obesity was more prevalent in women with $\mathrm{CAH}$, and waist circumference was obviously higher in both sexes than in healthy controls, consistent with the increased abdominal obesity and higher visceral to subcutaneous fat ratio linked to insulin resistance and inflammation, suggesting an unhealthy metabolic phenotype among adults with CAH (18).

It remains controversial whether hypertension, dyslipidemia, and hyperglycemia are more prevalent in adults with $\mathrm{CAH}$ than in healthy controls. The prevalence of hypertension was higher in the NIH and Swedish nationwide CAH cohorts $(4,5,8)$ and similar or lower in the CaHASE and French cohorts $(3,19)$. In our study, men with $\mathrm{CAH}$ but not women with $\mathrm{CAH}$ showed a higher prevalence of hypertension than the controls, which can be related to the relatively high proportion of fludrocortisone use and central obesity among men with $\mathrm{CAH}$ and the protective effect of estrogen on blood pressure among women with CAH. The prevalence of dyslipidemia and hyperglycemia was similar between adults with $\mathrm{CAH}$ and controls in this study. However, fasting glucose and HDL cholesterol levels in men with $\mathrm{CAH}$ and total cholesterol, triglyceride, and HDL cholesterol levels in women with $\mathrm{CAH}$ were higher than the values in controls, although a recent meta-analysis including 300 pediatric and 137 adults showed no difference in glucose and lipid levels (8). The result of higher HDLcholesterol levels in our patients with $\mathrm{CAH}$ remains to be reproduced in further studies, and the underlying mechanism also remains to be determined. However, Falhammar et al. suggested that older women with $\mathrm{CAH}$ had also higher lean mass which may explain the favorable lipid profile (20). Our study population mainly consisted of young adult patients who showed elevated androgen levels, suggesting poor disease control. Inconsistency in reporting the prevalence of metabolic comorbidities may have resulted from differences in patient age, glucocorticoid and mineralocorticoid doses, treatment target goals, disease control status, and 21hydroxylase activity.

We further analyzed factors that differed according to whether patients with $\mathrm{CAH}$ had more metabolic risk factors. Previous studies identified that adults with $\mathrm{CAH}$ are at risk for hyperandrogenism and iatrogenic hypercortisolism, both of which lead to obesity, insulin resistance, and cardiometabolic comorbidities $(5,6,9,10)$. In addition to glucocorticoid overtreatment, suppressed 17-OHP levels were related to obesity or metabolic morbidity $(3,11)$ as well as androgen excess, suggesting that poor disease control contributed to higher metabolic risk factors as shown in our study. 
TABLE 4 | Hormone status and treatment regimen in men with $\mathrm{CAH}$ according to the presence of testicular adrenal rest tumors ( $\mathrm{n}=70$ ) and women with $\mathrm{CAH}$ according to menstruation $(n=86)$.

\begin{tabular}{|c|c|c|c|c|c|c|}
\hline \multirow[t]{2}{*}{ Variables } & \multicolumn{3}{|c|}{ Men } & \multicolumn{3}{|c|}{ Women } \\
\hline & $\begin{array}{l}\text { TART (-) } \\
(\mathrm{N}=30)\end{array}$ & $\begin{array}{l}\text { TART (+) } \\
(\mathrm{N}=40)\end{array}$ & $P$ & $\begin{array}{l}\text { Irregular } \\
(n=50)\end{array}$ & $\begin{array}{l}\text { Regular } \\
(n=36)\end{array}$ & $P$ \\
\hline Age at evaluation, years & $27.0[22.0 ; 35.0]$ & $27.0[24.0 ; 31.0]$ & 0.957 & 29.5 [22.0;39.0] & $27.0[22.5 ; 34.5]$ & 0.277 \\
\hline Height, cm & $164.6 \pm 8.2$ & $162.2 \pm 6.1$ & 0.196 & $151.0[146.4 ; 156.5]$ & $155.3[151.6 ; 159.7]$ & 0.011 \\
\hline Weight, kg & $66.0[56.8 ; 76.4]$ & $67.4[57.4 ; 79.8]$ & 0.822 & $54.4[45.6 ; 58.6]$ & $52.0[44.7 ; 59.8]$ & 0.601 \\
\hline Body mass index, $\mathrm{kg} / \mathrm{m}^{2}$ & $24.0[21.4 ; 28.1]$ & $23.8[21.7 ; 30.6]$ & 0.474 & $23.2[20.2 ; 25.6]$ & $22.5[20.1 ; 25.8]$ & 0.768 \\
\hline Waist circumference (cm) & $89.9 \pm 11.1$ & $88.5 \pm 11.5$ & 0.669 & 87.0 [78.0;93.0] & $80.5[75.0 ; 90.0]$ & 0.136 \\
\hline Lean mass $(\mathrm{kg})$ & $26.9[24.0 ; 30.5]$ & $26.2[24.5 ; 29.1]$ & 0.702 & $20.7[17.9 ; 23.1]$ & $19.5[17.4 ; 21.9]$ & 0.788 \\
\hline Percentage lean mass (\%) & $39.8[37.6 ; 45.5]$ & $39.6[34.8 ; 42.8]$ & 0.371 & $35.1[32.2 ; 38.3]$ & $36.5[33.0 ; 41.6]$ & 0.345 \\
\hline Fat mass $(\mathrm{kg})$ & $22.3 \pm 7.9$ & $21.9 \pm 9.7$ & 0.865 & $21.1[18.8 ; 25.5]$ & $21.6[16.2 ; 24.9]$ & 0.570 \\
\hline Percentage fat mass (\%) & $31.3 \pm 7.4$ & $30.2 \pm 8.9$ & 0.657 & $39.0 \pm 6.9$ & $37.0 \pm 5.9$ & 0.270 \\
\hline 17-OHP, ng/mL & $58.2[20.7 ; 85.9]$ & 72.5 [48.6;100.9] & 0.098 & $49.5[28.5 ; 97.4]$ & $45.3[27.1 ; 68.0]$ & 0.203 \\
\hline $17-\mathrm{OHP}<10$ ng/mL & $3(10.0 \%)$ & $1(2.5 \%)$ & 0.307 & $4(8.0 \%)$ & $5(13.9 \%)$ & 0.482 \\
\hline Total testosterone, ng/mL & $4.2[3.3 ; 5.4]$ & $4.8[3.7 ; 6.2]$ & 0.314 & $0.7[0.3 ; 1.6]$ & $0.5[0.1 ; 0.7]$ & 0.086 \\
\hline DHEAS, $n g / m L$ & 885.5 [285.0;1396.0] & 584.0 [302.0;1348.0] & 0.963 & $462.5[199.0 ; 1559.0]$ & $251.0[102.5 ; 573.5]$ & 0.013 \\
\hline Plasma renin activity, $\mathrm{ng} / \mathrm{mL} / \mathrm{hr}$ & $8.1[4.2 ; 12.3]$ & $7.3[3.8 ; 19.1]$ & 0.748 & $8.6[4.6 ; 14.2]$ & $7.4[4.7 ; 11.2]$ & 0.458 \\
\hline Plasma renin activity $<3 \mathrm{ng} / \mathrm{mL} / \mathrm{hr}$ & $3(10.0 \%)$ & 7 (18.9\%) & 0.493 & $5(10.9 \%)$ & $4(12.5 \%)$ & 1.000 \\
\hline $\mathrm{ACTH}, \mathrm{pg} / \mathrm{mL}$ & $82.5[42.4 ; 699.2]$ & $187.0[46.9 ; 318.0]$ & 0.948 & $41.0[16.0 ; 125.8]$ & $58.9[35.5 ; 241.6]$ & 0.188 \\
\hline Adrenal thickness on $\mathrm{CT}, \mathrm{mm}^{\star}$ & $6.2[5.4 ; 7.4]$ & $6.1[4.1 ; 7.2]$ & 0.512 & $6.7[5.2 ; 8.4]$ & $6.0[4.5 ; 6.9]$ & 0.202 \\
\hline Adrenal tumors, n (\%) & $4(20.0 \%)$ & $4(16.7 \%)$ & 1.000 & $4(14.8 \%)$ & $1(5.3 \%)$ & 0.387 \\
\hline Glucocorticoid regimen, n (\%) & & & 1.000 & & & 0.649 \\
\hline Hydrocortisone & 1 (3.3\%) & 2 (5.0\%) & & $3(6.0 \%)$ & $4(11.1 \%)$ & \\
\hline Prednisolone & 29 (96.7\%) & 38 (95.0\%) & & 47 (94.0\%) & 32 (88.9\%) & \\
\hline Glucocorticoid dose, mg/day & $30.0[20.0 ; 30.0]$ & $30.0[20.0 ; 30.0]$ & 0.736 & $30.0[20.0 ; 30.0]$ & $27.5[20.0 ; 30.0]$ & 0.379 \\
\hline Fludrocortisone use, n (\%) & $24(80.0 \%)$ & $32(80.0 \%)$ & 1.000 & $29(58.0 \%)$ & 27 (75.0\%) & 0.161 \\
\hline
\end{tabular}

Data are shown as mean \pm standard deviation, median (interquartile range), or numbers (percentages). 17-OHP, 17-hydroxyprogesterone; DHEAS, dehydroepiandrosterone sulfate. ${ }^{*}$ Adrenal thickness was available in 43 men and 50 women.

Intriguingly, obese men with $\mathrm{CAH}$ presented with thick adrenal limbs, while obese women had high $17-\mathrm{OHP}$ and DHEAS levels. Few studies have examined the adrenal morphology of adults with $\mathrm{CAH}(6,21)$. Adrenal nodules were more frequently detected in poorly controlled patients with $\mathrm{CAH}$, and regressed in size after high-dose steroids (13). Adrenal hyperplasia and/or nodules have been reported in $29.3-45 \%$ of patients with CAH (22), with significant correlation with high levels of ACTH, 17-OHP, and plasma renin activity (6). Adrenal tumors were detected in 15\% (14/93) among our adult patients evaluated by CT. Despite the limitation of a single hormonal measurement in the morning due to the cross-sectional nature of this study, adrenal limb thickness or the presence of adrenal tumors could be a long-term disease control marker in adults with CAH.

Obese women with $\mathrm{CAH}$ showed higher 17-OHP levels than non-obese ones, suggesting the contribution of androgen excess. A similar phenomenon was demonstrated in polycystic ovary syndrome in postmenopausal women (23-25). Androgen excess drives visceral fat accumulation and induces the android phenotype in women with $\mathrm{CAH}(26,27)$. Even with continued treatment, patients may respond poorly to glucocorticoid treatment $(6,28)$ related to glucocorticoid receptor gene polymorphism in addition to low adherence to glucocorticoid therapy regimens (29). Further studies are warranted to determine optimal targets and androgen metabolites that reflect adequate hormonal control and ideal glucocorticoid regimens to minimize cardiometabolic comorbidities.
The presence of TART is the main factor of male infertility since it blocks the seminiferous tubules and leads to Leydig cell failure, which has a reported prevalence of around 37\% (14-86\%) depending on age and genotype $(5,6,19,30)$. In our study, TARTs were found in $57.1 \%$ of men with $\mathrm{CAH}$ who underwent testicular sonography. Since TARTs express adrenal-specific enzymes and ACTH and angiotensin II receptors (31), poor disease control and high ACTH or renin activity can lead to adrenocortical hyperplasia and TARTs $(5,32,33)$, although the lack of a correlation between 17-OHP levels and TARTs has been reported $(6,12,34)$. Although the present study failed to demonstrate a relationship between disease control and the presence of TARTs, in our previous study, TART size was related to the undertreatment percentage (35).

The prevalence of menstrual irregularity was up to $58.1 \%$ in the women with $\mathrm{CAH}$ in our study, which is consistent with that of a previous report of $30-75 \%$ depending on genotype (3). Women with $\mathrm{CAH}$ and irregular periods exhibited shorter stature and higher DHEAS levels, reflecting hyperandrogenism. Patients with CAH exposed to high androgens in childhood can experience earlier epiphyseal closure and short stature. Hyperandrogenism suppresses serum progesterone, which reduces luteinizing hormone pulsatility during the follicular phase and induces endometrial thinning, leading to oligo- or anovulation and oligo- or amenorrhea (36-38).

This cross-sectional study had several limitations. There were several missing values due to the retrospective study design. We could not assess the total cumulative doses of glucocorticoid or 
perform a longitudinal hormone assessment to determine disease control due to a lack of childhood data before the electronic medical record era. Since most patients were diagnosed before the genetic testing era, we could not analyze the patients' clinical or hormone characteristics according to genotype. When we assessed single hormone measurements in the morning at the last visit, only $7.3 \%$ of patients had well-controlled disease based on the earlymorning 17-OHP levels. Since undertreatment still affected most of our patients compared to those in previous reports (3), we could not compare the effect of undertreatment versus overtreatment on long-term outcomes. Androstenedione, which was known to be the reliable marker for disease control (1), was not checked due to the cost and unavailability. Although this cross-sectional design could not prove the causal relationship of disease itself or treatment effect with metabolic complications, our study had several strengths. First, it is the largest single-center Asian study of adults with CAH. We also compared age-, sex-, and ethnicitymatched controls to assess metabolic risk. We separately analyzed sex-specific indicators according to health outcomes and obtained different findings by sex. Adrenal thickness assessed by CT was incorporated into the variables to reflect long-term glucocorticoid exposure. Most patients had taken the same dosage of prednisolone in adulthood, thereby allowing us to compare their hormonal effects in patients with $\mathrm{CAH}$ without glucocorticoid dose interference.

\section{CONCLUSION}

The present study confirmed the higher prevalence of metabolic morbidities in young adults with $\mathrm{CAH}$ than in healthy controls. Moreover, adverse metabolic outcomes and menstrual irregularity were associated with poor disease control in our study subjects. Considering the harmful effects of poor disease control on longterm outcomes, compliance should be guaranteed. Early attention should be paid to identifying at-risk patients and regular followup provided to minimize cardiovascular risk in patients with CAH. Further studies are needed to elucidate the mechanisms leading to metabolic morbidity and the respective roles of androgen excess and glucocorticoid exposure.

\section{REFERENCES}

1. Speiser PW, Arlt W, Auchus RJ, Baskin LS, Conway GS, Merke DP, et al. Congenital Adrenal Hyperplasia Due to Steroid 21-Hydroxylase Deficiency: An Endocrine Society Clinical Practice Guideline. J Clin Endocrinol Metab (2018) 103(11):4043-88. doi: 10.1210/jc.2018-01865

2. Claahsen-van der Grinten HL, Speiser PW, Ahmed SF, Arlt W, Auchus RJ, Falhammar H, et al. Congenital Adrenal Hyperplasia - Current Insights in Pathophysiology, Diagnostics and Management. Endocr Rev (2021). doi: 10.1210/endrev/bnab016

3. Arlt W, Willis DS, Wild SH, Krone N, Doherty EJ, Hahner S, et al. Health Status of Adults With Congenital Adrenal Hyperplasia: A Cohort Study of 203 Patients. J Clin Endocrinol Metab (2010) 95(11):5110-21. doi: 10.1210/ jc.2010-0917

4. Falhammar H, Frisen L, Hirschberg AL, Norrby C, Almqvist C, Nordenskjold A, et al. Increased Cardiovascular and Metabolic Morbidity in Patients With 21Hydroxylase Deficiency: A Swedish Population-Based National Cohort Study. J Clin Endocrinol Metab (2015) 100(9):3520-8. doi: 10.1210/JC.2015-2093

\section{DATA AVAILABILITY STATEMENT}

The original contributions presented in the study are included in the article/supplementary files. Further inquiries can be directed to the corresponding authors.

\section{ETHICS STATEMENT}

The studies involving human participants were reviewed and approved by Seoul National University Hospital Institutional Review Board. Written informed consent for participation was not required for this study in accordance with the national legislation and the institutional requirements.

\section{AUTHOR CONTRIBUTIONS}

SL and JK contributed in the conception of the work, participated in the study design, and wrote the manuscript. YL contributed in the conception of the work, participated in the study design, and critically revised the manuscript. HJ, SK, CA, SK, and CS contributed in the conception of the work, performed statistical analyses, and critically revised the manuscript. All authors contributed to the article and approved the submitted version.

\section{FUNDING}

This study was funded by a donation from one CAH patient.

\section{ACKNOWLEDGMENTS}

We are grateful to Sei Won Yang, the emeritus professor of pediatrics at Seoul National University College of Medicine, and Seong Yeon Kim, the emeritus professor of internal medicine at Seoul National University College of Medicine. We also thank Serena Park for building up the database.

5. Finkielstain GP, Kim MS, Sinaii N, Nishitani M, Van Ryzin C, Hill SC, et al. Clinical Characteristics of a Cohort of 244 Patients With Congenital Adrenal Hyperplasia. J Clin Endocrinol Metab (2012) 97(12):4429-38. doi: 10.1210/ jc.2012-2102

6. Bachelot A, Golmard JL, Dulon J, Dahmoune N, Leban M, Bouvattier C, et al. Determining Clinical and Biological Indicators for Health Outcomes in Adult Patients With Childhood Onset of Congenital Adrenal Hyperplasia. Eur J Endocrinol (2015) 173(2):175-84. doi: 10.1530/EJE-14-0978

7. Falhammar H, Claahsen-van der Grinten H, Reisch N, Slowikowska-Hilczer J, Nordenstrom A, Roehle R, et al. Health Status in 1040 Adults With Disorders of Sex Development (DSD): A European Multicenter Study. Endocr Connect (2018) 7(3):466-78. doi: 10.1530/EC-18-0031

8. Tamhane S, Rodriguez-Gutierrez R, Iqbal AM, Prokop LJ, Bancos I, Speiser PW, et al. Cardiovascular and Metabolic Outcomes in Congenital Adrenal Hyperplasia: A Systematic Review and Meta-Analysis. J Clin Endocrinol Metab (2018) 103(11):4097-103. doi: 10.1210/jc.2018-01862

9. Zhang HJ, Yang J, Zhang MN, Liu CQ, Xu M, Li XJ, et al. Metabolic Disorders in Newly Diagnosed Young Adult Female Patients With Simple Virilizing 
21-Hydroxylase Deficiency. Endocrine (2010) 38(2):260-5. doi: 10.1007/ s12020-010-9382-9

10. Paizoni L, Auer MK, Schmidt H, Hubner A, Bidlingmaier M, Reisch N. Effect of Androgen Excess and Glucocorticoid Exposure on Metabolic Risk Profiles in Patients With Congenital Adrenal Hyperplasia Due to 21-Hydroxylase Deficiency. J Steroid Biochem Mol Biol (2020) 197:105540. doi: 10.1016/j.jsbmb.2019.105540

11. Torky A, Sinaii N, Jha S, Desai J, El-Maouche D, Mallappa A, et al. Cardiovascular Disease Risk Factors and Metabolic Morbidity in a Longitudinal Study of Congenital Adrenal Hyperplasia. J Clin Endocrinol Metab (2021). doi: 10.1210/clinem/dgab133

12. Reisch N, Rottenkolber M, Greifenstein A, Krone N, Schmidt H, Reincke M, et al. Testicular Adrenal Rest Tumors Develop Independently of Long-Term Disease Control: A Longitudinal Analysis of 50 Adult Men With Congenital Adrenal Hyperplasia Due to Classic 21-Hydroxylase Deficiency. J Clin Endocrinol Metab (2013) 98(11):E1820-6. doi: 10.1210/jc.2012-3181

13. Giacaglia LR, Mendonca BB, Madureira G, Melo KF, Suslik CA, Arnhold IJ, et al. Adrenal Nodules in Patients With Congenital Adrenal Hyperplasia Due to 21Hydroxylase Deficiency: Regression After Adequate Hormonal Control. J Pediatr Endocrinol Metab (2001) 14(4):415-9. doi: 10.1515/JPEM.2001.14.4.415

14. Kweon S, Kim Y, Jang MJ, Kim Y, Kim K, Choi S, et al. Data Resource Profile: The Korea National Health and Nutrition Examination Survey (KNHANES). Int J Epidemiol (2014) 43(1):69-77. doi: 10.1093/ije/dyt228

15. Seo MH, Lee WY, Kim SS, Kang JH, Kang JH, Kim KK, et al. 2018 Korean Society for the Study of Obesity Guideline for the Management of Obesity in Korea. J Obes Metab Syndr (2019) 28(1):40-5. doi: 10.7570/jomes.2019.28.1.40

16. Alberti KG, Eckel RH, Grundy SM, Zimmet PZ, Cleeman JI, Donato KA, et al. Harmonizing the Metabolic Syndrome: A Joint Interim Statement of the International Diabetes Federation Task Force on Epidemiology and Prevention; National Heart, Lung, and Blood Institute; American Heart Association; World Heart Federation; International Atherosclerosis Society; and International Association for the Study of Obesity. Circulation (2009) 120 (16):1640-5. doi: 10.1161/CIRCULATIONAHA.109.192644

17. Kong SH, Kim JH, Shin CS. Contralateral Adrenal Thinning as a Distinctive Feature of Mild Autonomous Cortisol Excess of the Adrenal Tumors. Eur J Endocrinol (2020) 183(3):325-33. doi: 10.1530/EJE-20-0301

18. Kim MS, Ryabets-Lienhard A, Dao-Tran A, Mittelman SD, Gilsanz V, Schrager SM, et al. Increased Abdominal Adiposity in Adolescents and Young Adults With Classical Congenital Adrenal Hyperplasia Due to 21-Hydroxylase Deficiency. J Clin Endocrinol Metab (2015) 100(8):E1153-59. doi: 10.1210/jc.2014-4033

19. Bouvattier C, Esterle L, Renoult-Pierre P, de la Perriere AB, Illouz F, Kerlan V, et al. Clinical Outcome, Hormonal Status, Gonadotrope Axis, and Testicular Function in 219 Adult Men Born With Classic 21-Hydroxylase Deficiency. A French National Survey. J Clin Endocrinol Metab (2015) 100(6):2303-13. doi: 10.1210/jc.2014-4124

20. Falhammar H, Filipsson H, Holmdahl G, Janson PO, Nordenskjold A, Hagenfeldt K, et al. Metabolic Profile and Body Composition in Adult Women With Congenital Adrenal Hyperplasia Due to 21-Hydroxylase Deficiency. J Clin Endocrinol Metab (2007) 92(1):110-6. doi: 10.1210/jc.2006-1350

21. Reisch N, Scherr M, Flade L, Bidlingmaier M, Schwarz HP, Muller-Lisse U, et al. Total Adrenal Volume But Not Testicular Adrenal Rest Tumor Volume Is Associated With Hormonal Control in Patients With 21-Hydroxylase Deficiency. J Clin Endocrinol Metab (2010) 95(5):2065-72. doi: 10.1210/jc.2009-1929

22. Nermoen I, Falhammar H. Prevalence and Characteristics of Adrenal Tumors and Myelolipomas in Congenital Adrenal Hyperplasia: A Systematic Review and Meta-Analysis. Endocr Pract (2020) 26(11):1351-65. doi: 10.4158/EP-2020-0058

23. Wild RA, Carmina E, Diamanti-Kandarakis E, Dokras A, Escobar-Morreale HF, Futterweit W, et al. Assessment of Cardiovascular Risk and Prevention of Cardiovascular Disease in Women With the Polycystic Ovary Syndrome: A Consensus Statement by the Androgen Excess and Polycystic Ovary Syndrome (AE-PCOS) Society. J Clin Endocrinol Metab (2010) 95(5):2038-49. doi: 10.1210/jc.2009-2724

24. Janssen I, Powell LH, Kazlauskaite R, Dugan SA. Testosterone and Visceral Fat in Midlife Women: The Study of Women's Health Across the Nation (SWAN) Fat Patterning Study. Obes (Silver Spring) (2010) 18(3):604-10. doi: 10.1038/oby.2009.251

25. Diamanti-Kandarakis E, Dunaif A. Insulin Resistance and the Polycystic Ovary Syndrome Revisited: An Update on Mechanisms and Implications. Endocr Rev (2012) 33(6):981-1030. doi: 10.1210/er.2011-1034
26. Rosenfield RL, Ehrmann DA. The Pathogenesis of Polycystic Ovary Syndrome (PCOS): The Hypothesis of PCOS as Functional Ovarian Hyperandrogenism Revisited. Endocr Rev (2016) 37(5):467-520. doi: 10.1210/er.2015-1104

27. Pasquali R, Vicennati V, Gambineri A, Pagotto U. Sex-Dependent Role of Glucocorticoids and Androgens in the Pathophysiology of Human Obesity. Int J Obes (Lond) (2008) 32(12):1764-79. doi: 10.1038/ijo.2008.129

28. Han TS, Conway GS, Willis DS, Krone N, Rees DA, Stimson RH, et al. Relationship Between Final Height and Health Outcomes in Adults With Congenital Adrenal Hyperplasia: United Kingdom Congenital Adrenal Hyperplasia Adult Study Executive (CaHASE). J Clin Endocrinol Metab (2014) 99(8):E1547-55. doi: 10.1210/jc.2014-1486

29. Moreira RP, Gomes LG, Mendonca BB, Bachega TA. Impact of Glucocorticoid Receptor Gene Polymorphisms on the Metabolic Profile of Adult Patients With the Classical Form of 21-Hydroxylase Deficiency. PloS One (2012) 7(9):e44893. doi: 10.1371/journal.pone.0044893

30. Engels M, Span PN, van Herwaarden AE, Sweep F, Stikkelbroeck N, Claahsenvan der Grinten HL. Testicular Adrenal Rest Tumors: Current Insights on Prevalence, Characteristics, Origin, and Treatment. Endocr Rev (2019) 40 (4):973-87. doi: 10.1210/er.2018-00258

31. Claahsen-van der Grinten HL, Otten BJ, Sweep FC, Span PN, Ross HA, Meuleman EJ, et al. Testicular Tumors in Patients With Congenital Adrenal Hyperplasia Due to 21-Hydroxylase Deficiency Show Functional Features of Adrenocortical Tissue. J Clin Endocrinol Metab (2007) 92(9):3674-80. doi: $10.1210 /$ jc.2007-0337

32. Martinez-Aguayo A, Rocha A, Rojas N, Garcia C, Parra R, Lagos M, et al. Testicular Adrenal Rest Tumors and Leydig and Sertoli Cell Function in Boys With Classical Congenital Adrenal Hyperplasia. J Clin Endocrinol Metab (2007) 92(12):4583-9. doi: 10.1210/jc.2007-0383

33. Yu MK, Jung MK, Kim KE, Kwon AR, Chae HW, Kim DH, et al. Clinical Manifestations of Testicular Adrenal Rest Tumor in Males With Congenital Adrenal Hyperplasia. Ann Pediatr Endocrinol Metab (2015) 20(3):155-61. doi: 10.6065/apem.2015.20.3.155

34. Delfino M, Elia J, Imbrogno N, Argese N, Mazzilli R, Toscano V, et al. Testicular Adrenal Rest Tumors in Patients With Congenital Adrenal Hyperplasia: Prevalence and Sonographic, Hormonal, and Seminal Characteristics. J Ultrasound Med (2012) 31(3):383-8. doi: 10.7863/jum.2012.31.3.383

35. Kang MJ, Kim JH, Lee SH, Lee YA, Shin CH, Yang SW. The Prevalence of Testicular Adrenal Rest Tumors and Associated Factors in Postpubertal Patients With Congenital Adrenal Hyperplasia Caused by 21-Hydroxylase Deficiency. Endocr J (2011) 58(6):501-8. doi: 10.1507/endocrj.K11E-034

36. Bachelot A, Chakhtoura Z, Plu-Bureau G, Coudert M, Coussieu C, Badachi Y, et al. Influence of Hormonal Control on LH Pulsatility and Secretion in Women With Classical Congenital Adrenal Hyperplasia. Eur J Endocrinol (2012) 167(4):499-505. doi: 10.1530/EJE-12-0454

37. Mulaikal RM, Migeon CJ, Rock JA. Fertility Rates in Female Patients With Congenital Adrenal Hyperplasia Due to 21-Hydroxylase Deficiency. $N$ Engl J Med (1987) 316(4):178-82. doi: 10.1056/NEJM198701223160402

38. Merke DP, Auchus RJ. Congenital Adrenal Hyperplasia Due to 21Hydroxylase Deficiency. N Engl J Med (2020) 383(13):1248-61. doi: 10.1056/NEJMra1909786

Conflict of Interest: The authors declare that the research was conducted in the absence of any commercial or financial relationships that could be construed as a potential conflict of interest.

Publisher's Note: All claims expressed in this article are solely those of the authors and do not necessarily represent those of their affiliated organizations, or those of the publisher, the editors and the reviewers. Any product that may be evaluated in this article, or claim that may be made by its manufacturer, is not guaranteed or endorsed by the publisher.

Copyright $\odot 2021$ Lim, Lee, Jang, Kong, Ahn, Kim, Shin and Kim. This is an openaccess article distributed under the terms of the Creative Commons Attribution License (CC BY). The use, distribution or reproduction in other forums is permitted, provided the original author(s) and the copyright owner(s) are credited and that the original publication in this journal is cited, in accordance with accepted academic practice. No use, distribution or reproduction is permitted which does not comply with these terms. 